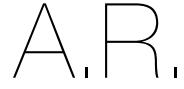

ARTIGO DE REVISÃO

1 Faculdade de Farmácia

da Universidade de

Coimbra,

3000-548, Coimbra,

Portugal

Endereço para correspondência:

Ana Beatriz F Silva

Faculdade de Farmácia da

Universidade de Coimbra

3000-548, Coimbra, Portug a

anasilva3327@gmail.com

Histórico do artigo:

Recebido a 1 de marco de 2021 Aceite $\mathrm{a} 8$ de outubro de 2021

\title{
ALIMENTOS PARA DESPORTISTAS: DEFINIÇÃO E ATUALIDADE
}

\author{
ATHLETES FOOD: DEFINITION AND CURRENT VIEWS ON IT
}

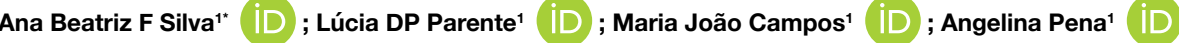

\section{RESUMO}

No contexto desportivo, é muito frequente o uso de alimentos para desportistas. No entanto, estes devem ser encarados como uma estratégia complementar, como forma de auxílio nos seus objetivos enquanto atleta, aquando da necessidade de uma combinação específica de nutrientes essenciais. Neste artigo de revisão é analisada a regulamentação vigente e recomendações dos alimentos para desportistas. Além disso, ainda é demonstrado o papel crucial do Nutricionista no aconselhamento dos alimentos para desportistas, bem como no esclarecimento das diferenças entre estes últimos e suplementos alimentares.

\section{PALAVRAS-CHAVE}

Alimentos para desportistas, Legislação, Rendimento desportivo, Suplemento Alimentar

ABSTRACT

In the sports context, the use of food for athletes is very common. However, these should be seen as a complementary strategy, as a way of reaching the athlete's goals, when they need a specific combination of essential nutrients. In this review article, the current regulations and food recommendations for athletes are analyzed. In addition, the crucial role of the Nutritionist is demonstrated in advising on foods for athletes, as well as in clarifying the differences between the latter and food supplements.

KEYWORDS

Food for athletes, Legislation, Athletic performance, Food supplement

\section{INTRODUÇÃo}

A alimentação é um dos pilares do sucesso desportivo de um atleta. A intensidade, o nível, a duração e frequência do exercício físico são aspetos a considerar na intervenção nutricional, já que estão diretamente relacionadas com as necessidades nutricionais, sendo que estas últimas necessitam de ser adaptadas a cada indivíduo (1).

É notório que, ao longo dos anos, tem existido uma maior consciencialização da importância de uma correta alimentação no mundo desportivo, assumindo uma posição relevante na vida de um desportista, uma vez que o estado nutricional e a alimentação têm efeitos significativos no seu rendimento desportivo (2).

A ingestão energética é um aspeto importante, sendo fulcral a ingestão de uma quantidade suficiente de calorias que supram os gastos dos atletas (1). O défice energético pode provocar perdas de massa muscular, fracasso no desempenho, aumento da suscetibilidade a lesões, aumento do cansaço e diminuição da coordenação e da concentração. Enquanto que a necessidade energética de um treino mais leve é de $25-35 \mathrm{kcal} / \mathrm{kg} / \mathrm{dia}$, a de um treino mais intenso é superior, correspondendo a $50-80 \mathrm{kcal} /$ $\mathrm{kg} / \mathrm{dia}$. Assim, os desportistas, muitas vezes, recorrem a alternativas, como é o caso das barras energéticas (3). Quando se pretende assegurar o cumprimento das necessidades nutricionais ou potenciar os resultados do treino, a suplementação alimentar e/ou alimentos destinados a desportistas (AD) são uma alternativa (2). Apesar da enorme dimensão característica do mercado da suplementação alimentar, nem todos os AD e suplementos alimentares (SA) possuem evidência científica legitima que justifique a sua utilização. O uso incorreto destes produtos poderá ter efeitos negativos a nível do rendimento e da saúde de quem os consome, sendo o aconselhamento profissional de extrema relevância. A falta de acompanhamento, poderá conduzir a situações de doping não intencional, através do consumo de suplementos contendo substâncias proibidas pela Agência Mundial Antidoping (AMA). Assim sendo, o propósito e o estado de saúde do atleta, as exigências da modalidade, o custobenefício do uso desse suplemento, as consequências para a saúde e performance e o possível resultado positivo num teste antidopagem, são fatores a ponderar antes da toma de qualquer suplemento (2). 
Face ao acima exposto, é importante realçar que os AD nunca devem ser encarados como substitutos da dieta dos atletas, mas sim como uma estratégia extra em situações em que seja vantajosa uma combinação específica de nutrientes essenciais $(2,4)$.

\section{METODOLOGIA}

Para a execução deste trabalho foi realizada uma revisão da literatura científica disponível na Pubmed bem como da Regulamentação Europeia e Nacional. A pesquisa de informação para o presente artigo decorreu entre 28 de outubro de 2020 e 17 de fevereiro de 2021, tendo sido realizada uma atualização de informação durante o mês de julho de 2021. Na procura da informação, foram utilizadas como palavras-chave de pesquisa: "Alimentos para desportistas", "Athletic Performance", "Food for sportsmen", "Food supplement”, "legislação", "Rendimento desportivo", "Suplemento Alimentar". Dos 15 artigos encontrados, para a redação deste artigo foram utilizados 14. Foram excluídos artigos onde os alimentos para desportistas eram classificados como géneros alimentícios comuns, destinados ao consumo corrente ou géneros alimentícios destinados a uma alimentação especial (referentes à legislação em vigor até 20 de julho de 2016).

\section{Enquadramento}

Até 2016, os AD eram classificados em géneros alimentícios comuns, destinados ao consumo corrente ou géneros alimentícios destinados a uma alimentação especial. Estes últimos incluíam os alimentos adaptados a um esforço muscular intenso, sobretudo para desportistas (5).

Todavia, de acordo com o Relatório da Comissão ao Parlamento Europeu e ao Conselho sobre os AD, a classificação suscitava dúvidas, sendo difícil percecionar se um determinado produto era considerado de alimentação especial para os desportistas, ou se era um alimento de consumo corrente, enriquecido com determinados nutrientes e objeto de uma alegação de saúde dirigida aos praticantes de desporto (6). A 20 de julho de 2016, a entrada em vigor do Regulamento (UE) n. ${ }^{\circ}$ 609/2013 determinou que os AD passassem a ser considerados géneros alimentícios comuns, deixando de estar disponível a segunda classificação relativa à alimentação especial. Assim, para serem colocados no mercado, estes produtos não carecem de autorização por parte da Direção-Geral de Alimentação e Veterinária (DGAV) autoridade competente responsável em Portugal, sendo orientados pelas regras horizontais da legislação alimentar que fornecem as disposições necessárias relativamente à segurança alimentar destes produtos (5).

Porém, este tipo de alimentos detém características próprias, que podem dificultar o seu enquadramento como género alimentício comum, especialmente quando confrontados com suplementos alimentares, uma vez que pelo tipo de rotulagem e pela toma em forma doseada, poderão ser considerados SA. No entanto, existem diferenças entre as definições de "suplemento alimentar" e de "alimento para desportista", as quais estão enumeradas na Tabela 1 (5).

De acordo com as linhas orientadoras fornecidas pela DGAV, na ausência de legislação harmonizada, uma "unidade medida de quantidade reduzida" corresponde, no máximo, a 25 g ou $25 \mathrm{~mL}$. Por outro lado, de acordo com a dose diária máxima indicada, considera-se irrelevante um aporte energético igual ou inferior a 200 $\mathrm{KJ}$ (50 Kcal) por dia. As características anteriormente mencionadas são relativas aos SA. Em oposição, uma unidade de medida de um género alimentício comum, onde se inserem os $A D$, é apresentada em forma doseada em unidades superiores a $25 \mathrm{~g}$ ou $25 \mathrm{~mL}$ e/ou fornece mais de $50 \mathrm{kcal}$ no conjunto da toma diária. Não obstante, alguns $A D$ podem continuar a ser enquadrados como $S A$, seguindo os seguintes critérios: apresentação necessariamente em forma doseada (comprimidos, cápsulas, saquetas e outras formas análogas às farmacológicas, incluindo colheres-medida, copos, doseadores), destinarem-se a ser consumidos em unidades medidas de quantidade reduzida (no máximo, $25 \mathrm{~g}$ ou $25 \mathrm{~mL}$ ), podendo haver várias tomas por dia, mas cada toma não pode ultrapassar o valor indicado e, por fim, o valor energético total da toma diária não deve exceder as 50 kcal. Assim, é da competência do operador económico decidir qual o enquadramento para o produto que vai colocar no mercado (5).

\section{Rotulagem e Composição}

Tal como referido anteriormente, os AD são regidos pelas regras horizontais da legislação alimentar, nomeadamente pelo Regulamento (CE) n. ${ }^{\circ}$ 178/2002, do Parlamento Europeu e do Conselho, que determina os princípios e normas gerais da legislação alimentar, cria a Autoridade Europeia para a Segurança dos Alimentos (EFSA) e estabelece procedimentos em matéria de segurança dos géneros alimentícios (7). Em relação às informações contidas nos rótulos, estas são fornecidas em concordância com o Regulamento (CE) n. ${ }^{\circ} 1169 / 2011$, do Parlamento Europeu e do Conselho, de 25 de outubro de 2011 relativo à prestação de informação aos consumidores sobre os géneros alimentícios. Os géneros alimentícios devem conter uma lista de informações obrigatórias que possibilite ao consumidor final a sua adequada identificação e utilização, permitindo escolhas adaptadas às suas necessidades alimentares: a) denominação do género alimentício; b) lista de ingredientes; c) indicação de todos os ingredientes ou determinados auxiliares tecnológicos ou derivados de uma substância ou produto que provoquem alergias ou intolerâncias, utilizados no fabrico ou na preparação de um género alimentício e que continuem presentes no produto acabado, mesmo sob uma forma alterada; d) quantidade de determinados ingredientes ou categorias de ingredientes; e) quantidade líquida do género alimentício; f) data de durabilidade mínima ou data-limite de consumo; g) condições especiais de conservação e/ou condições de utilização; h) nome ou firma e endereço do operador da empresa do setor alimentar; i) país de origem ou local de proveniência quando previsto; j) modo de emprego, quando a sua omissão dificultar uma utilização adequada do género alimentício; k) relativamente às bebidas com um título alcoométrico volúmico superior a 1,2\%, o título alcoométrico volúmico adquirido; I) uma declaração nutricional (8).

As alegações nutricionais e de saúde presentes nos rótulos devem cumprir o Regulamento (CE) n. ${ }^{\circ}$ 1924/2006 do Parlamento Europeu e do Conselho de 20 de dezembro de 2006, relativo às alegações nutricionais e de saúde sobre os alimentos (9). No Regulamento (UE) n. ${ }^{\circ}$ 432/2012 da Comissão, de 16 de maio, que estabelece uma

\section{Tabela 1}

Diferenças entre Suplementos Alimentares e Alimentos para desportistas

\begin{tabular}{ll}
\multicolumn{1}{c}{ SUPLEMENTOS ALIMENTARES } & \multicolumn{1}{c}{ ALIMENTOS PARA DESPORTISTAS } \\
$\begin{array}{l}\text { Unidade de medida de quantidade } \\
\text { reduzida: } \leq 25 \mathrm{~g} \text { ou } 25 \mathrm{~mL} \text {, por toma }\end{array}$ & $\begin{array}{l}\text { Unidade de medida: }>25 \mathrm{~g} \text { ou } 25 \mathrm{~mL} \\
\text { por toma }\end{array}$ \\
\hline $\begin{array}{l}\text { Aporte energético irrelevante: } \leq 200 \mathrm{~kJ} \\
\text { (50 kcal) por dia }\end{array}$ & $\begin{array}{l}\text { Aporte energético relevante: }>200 \mathrm{~kJ}(50 \\
\text { kcal) por dia }\end{array}$ \\
\hline $\begin{array}{l}\text { Forma doseada: comprimidos, cápsulas, } \\
\text { saquetas e outras formas análogas às } \\
\text { farmacológicas, incluindo colheres- } \\
\text {-medida, copos, doseadores. }\end{array}$ & $\begin{array}{l}\text { Comercializados, geralmente, em grandes } \\
\text { embalagens de pó }\end{array}$ \\
\hline
\end{tabular}

DGAV. Produtos Fronteira entre "Suplementos Alimentares" e "Alimentos para Desportistas." 2016 . 
lista de alegações de saúde permitidas relativas a alimentos que não referem a redução de um risco de doença ou o desenvolvimento e a saúde das crianças, estão referenciadas alegações de saúde admitidas alusivas à atividade física. Neste contexto evidenciam-se: a creatina que alega aumentar o desempenho físico durante exercícios repetidos de curta duração e alta intensidade; as soluções eletrolíticas que contêm hidratos de carbono que alegam aumentar a absorção de água durante o exercício físico; a vitamina $\mathrm{C}$ que contribui para o normal funcionamento do sistema imunitário tanto durante como após o exercício físico intenso; e as proteínas que alegam contribuir para o crescimento da massa muscular (10).

Atualmente, não é exigido que o rótulo dos $A D$ forneça informações relativas ao seu modo de utilização, salvo se a sua omissão dificultar uma utilização adequada do género alimentício (8).

\section{Alimentos Destinados a Desportistas}

De acordo com o relatório da Food Chain Evaluation Consortium (FCEC), AD são todos os produtos alimentares destinados a desportistas, independentemente da legislação da União Europeia responsável pela sua introdução no mercado.

Segundo o relatório da FCEC (2015), os AD existentes no mercado poderão ser categorizados em três grupos: (1) bebidas isotónicas, (2) produtos (à base de proteínas) para ganho de massa muscular e recuperação após a prática de atividade física e (3) produtos para aumentar a energia e desempenho e produtos para suplementação contínua de desportistas (6).

Os alimentos para desportistas compreendem, por exemplo, as barras desportivas, géis desportivos, suplementos de eletrólitos e suplementos de refeições líquidos. Estas são opções vantajosas para atender aos objetivos nutricionais, essencialmente quando há problemas no consumo de alimentos (devido a problemas gastrointestinais ou ao fraco acesso ao consumo de nutrientes) (1).

\section{a) Bebidas Isotónicas}

As bebidas isotónicas são compostas por água, glúcidos e eletrólitos (sódio, potássio, cálcio e magnésio) e são utilizadas com o objetivo de hidratar, repor os eletrólitos e aumentar a resistência e o desempenho do atleta $(2,11)$. Por isso, evidências científicas têm associado estas bebidas a um aumento da "performance" desportiva (11).

Para que a hidratação seja adequada, as bebidas ingeridas durante a competição devem ser isotónicas (200-320 mOsm / kg de água) (12). Estes produtos estão disponíveis na sua forma final (pronta a consumir) ou concentrada (pó ou líquido).

\section{b) Produtos à Base de Proteínas}

De forma a assegurar a síntese e recuperação proteica após o exercício físico, as recomendações diárias de ingestão de proteína para atletas são ligeiramente superiores às da população em geral, sendo 1 a 2 g/kg de peso corporal e 0,8 $\mathrm{g} / \mathrm{kg}$ de peso corporal, respetivamente $(1,13)$. No contexto desportivo, o consumo excessivo de proteína poderá conduzir a uma redução da ingestão de hidratos de carbono, prejudicando assim o rendimento (2).

Os suplementos proteicos mais utilizados são as proteínas presentes no leite, nomeadamente a whey (ou proteína de soro) e a caseína. A whey possui na sua constituição todos os aminoácidos essenciais, em especial a leucina. Além disso, apresenta uma grande proporção de aminoácidos de cadeia ramificada (BCAAs), particularmente a valina, leucina e isoleucina, importante na síntese proteica e anabolismo proteico muscular. Estes aminoácidos são eficientemente absorvidos e utilizados pelo organismo, sendo a whey, por essa razão, considerada de rápida absorção. Desta forma, esta última é muito utilizada por desportistas após a prática de exercício (14).

Por outro lado, a caseína é uma proteína de absorção mais lenta, apresentando a capacidade de inibir o catabolismo muscular aquando da sua ingestão. É importante sublinhar que pelo facto de impedir a degradação proteica e oxidação de aminoácidos que se sucedem durante o jejum noturno, a sua ingestão é preferencialmente à ceia (2). Posto isto, o leite devido ao seu conteúdo em caseína e proteína de soro, tem vindo a demonstrar ser um alimento que estimula o anabolismo proteico muscular (2).

\section{c) Produtos para Aumentar a Energia e Desempenho}

Nesta categoria incluem-se uma enorme variedade de ingredientes, de acordo com a tipologia de produto (12).

A cafeína é um dos ingredientes presente em produtos que procuram aumentar energia. De notar que alguns estudos referem que o seu consumo promove a performance desportiva e aumento de força muscular (12). De acordo com relatório da EFSA, a cafeína revela efeito ergogénico com doses entre os 3 e os $8 \mathrm{mg} / \mathrm{kg}$ de peso corporal quando ingerida antes do treino (12).

Este último grupo de produtos pode-se encontrar sob várias formas, nomeadamente: alimentos, liofilizados, prontos-a-consumir ou cápsulas/comprimidos (12).

\section{Vantagens e Desvantagens}

Os benefícios dos $A D$ incluem o facto de estes poderem combinar vários nutrientes essenciais numa única fonte. A sua tecnologia de embalagem também é vantajosa, pois torna os alimentos mais fáceis de transportar, armazenar, preparar e consumir, principalmente antes, durante ou após competições e treinos.

Em contrapartida, estes produtos são mais caros que os restantes géneros alimentícios comuns.

Estes alimentos possuem na sua constituição nutrientes específicos, tornando-se o seu uso vantajoso nos momentos em que uma combinação específica de nutrientes seja necessária. Assim sendo, não devem ser encarados como substitutos dietéticos para atletas, mas sim como uma estratégia complementar (4).

\section{CONCLUSÕES E ANÁLISE CRÍTICA}

É percetível que uma adequada alimentação contribui para o natural crescimento e desenvolvimento, para a redução do risco de doenças e lesões e ainda para uma otimização do desempenho desportivo, estando subjacente uma garantia de saúde e bem-estar (2). Os AD podem contribuir, notavelmente, para a vida de um atleta, fornecendo nutrientes que auxiliam na adaptação ao treino (por exemplo, proteína) e na promoção do desempenho (por exemplo, hidratos de carbono e líquidos/eletrólitos) (4). O uso de suplementos nutricionais e alimentos destinados para desportistas deve ser consciente, sendo necessária uma validação científica da sua eficácia no aumento do rendimento desportivo e/ou para atingir as necessidades nutricionais específicas (2).

No entanto, como são produtos de livre acesso, a sua aquisição nem sempre é consciente e ponderada. Neste sentido, os atletas devem possuir uma adequada nutrição, devendo procurar um nutricionista especializado que aconselhe o uso consciente destes produtos de acordo com o perfil nutricional de cada indivíduo. Também é da competência deste profissional da área da saúde adequar a cada desportista um plano alimentar tendo em conta o seu estado nutricional, modalidade de atividade física praticada. 


\section{REFERÊNCIAS BIBLIOGRÁFICAS}

1. Thomas DT, Erdman KA, Burke LM. Nutrition and Athletic Performance. Med Sci Sport Exerc [Internet]. 2016 Mar;48(3):543-68. Available from: http://journals.Iww. com/00005768-201603000-00025

2. Sousa M, Teixeira VH, Graça P. Nutrição no Desporto. Direção Geral de Saúde. Programa Nacional para a Promoção da Alimentação Saudável; 2016. 48 p.

3. Kreider RB, Wilborn CD, Taylor L, Campbell B, Almada AL, Collins R, et al. ISSN exercise \& sport nutrition review: research \& recommendations. J Int Soc Sports Nutr [Internet]. 2010 Dec 1;15(7):43. Available from: https://jissn.biomedcentral.com/articles/10.1186/1550-2783-7-7

4. Peeling P, Castell LM, Derave W, de Hon O, Burke LM. Sports Foods and Dietary Supplements for Optimal Function and Performance Enhancement in Track-and-Field Athletes. Int J Sport Nutr Exerc Metab [Internet]. 2019 Mar 1;29(2):198-209. Available from: https://journals. humankinetics.com/view/journals/jisnem/29/2/article-p198.xml. 5. DGAV. Produtos Fronteira entre "Suplementos Alimentares" e "Alimentos para Desportistas." 2016.

6. Comissão Europeia. Relatório da comissão ao parlamento europeu e ao conselho sobre os alimentos destinados a desportistas [Internet]. Bruxelas; 2016. Available from: https://ec.europa.eu/food/sites/food/files/safety/docs/fs_labelling-nutrition_special_report-2016-402_en.pdf.

7. Parlamento Europeu; Conselho da União Europeia. Regulamento (CE) N. ${ }^{\circ} 178 / 2002$ de 28 de Janeiro de 2002 [Internet]. Jornal Oficial da União Europeia. 2002. Available from: https://eur-lex.europa.eu/legal-content/PT/TXT/?uri=CELEX\%3A32002R0178. 8. Parlamento Europeu; Conselho da União Europeia. Regulamento (UE) N.O 1169/2011 de 25 de Outubro de 2011 [Internet]. Vol. L 304, Jornal Oficial da União Europeia. 2011. Available from: https://eur-lex.europa.eu/legal-content/pt/TXT/?uri=CELEX\%3A32011R1169.

9. Parlamento Europeu; Conselho da União Europeia. Regulamento (CE) n.o 1924/2006 de 20 de Dezembro de 2006 [Internet]. Jornal Oficial da União Europeia. 2006. Available from: https://eur-lex.europa.eu/legal-content/PT/ALL/?uri=CELEX\%3A32006R1924 10. Comissão Europeia. Regulamento (UE) No 432/2012 de 16 de maio de 2012 [Internet]. Jornal Oficial da União Europeia. 2012. Available from: https://eur-lex.europa eu/legal-content/PT/TXT/?uri=celex\%3A32012R0432.

11. Scientific and technical assistance on food intended for sportspeople. EFSA Support Publ [Internet]. 2015;12(9):32. Available from: https://www.efsa.europa.eu/en/ supporting/pub/en-871.

12. EFSA. 2015. Scientific and Technical Assistance on Food Intended for Sportspeople. Edited by European Food Safety Authority.2015.

13. Phillips SM, Moore DR, Tang JE. A Critical Examination of Dietary Protein Requirements, Benefits, and Excesses in Athletes. Int J Sport Nutr Exerc Metab [Internet] 2007 Feb;17(1):S58-76. Available from: https://journals.humankinetics.com/view/ journals/ijsnem/17/s1/article-pS58.xml.

14. Sousa GT, Lira FS, Rosa JC, de Oliveira EP, Oyama LM, Santos R V, et al. Dietary whey protein lessens several risk factors for metabolic diseases: a review. Lipids Health Dis [Internet]. 2012;11(1):67. Available from: http://lipidworld.biomedcentral. com/articles/10.1186/1476-511X-11-67. 